\title{
Charting Academic Library Staffing: Data from National Surveys
}

\section{Rachel Applegate}

\begin{abstract}
Many issues in academic library practice and research are affected by staffing patterns. To provide an overview of librarian distribution among large, medium, and small institutions, librarian to nonlibrarian ratios, and ratios of library staff to students and faculty, a database comprising 1,380 fouryear nonspecialized U.S. academic institutions was constructed. Among other findings, these descriptive data show that academic librarians are distributed bimodally, with a few large libraries employing about half of all academic librarians. Findings concerning librarians, institutions, and staffing ratios by library size, Carnegie classification, and control are presented.
\end{abstract}

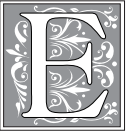

mployment, research, and assessment are all areas in which the question can be raised, "What is a typical academic library?" Library school students wonder what kinds of institutions they might be joining. Researchers make decisions about the libraries they will include in a particular study, or wonder how closely librarian respondents represent the larger population. In determining the adequacy-or excellence- of a library, the ACRL "Standards for Libraries in Higher Education" urges comparisons with peer institutions.

The following presents descriptive perspectives on librarians in the American academic universe. The data were derived from federally organized national surveys of institutions and libraries, with a nearly 95\% return rate. These data are thus far more comprehensive than previously available.

\section{Existing resources and techniques}

From a job-seeking student perspective, the main sources of information about potential academic positions are anecdotes from professors, colleagues, and internship sites, informal reviews of job postings, the Library Journal survey of placements and salaries (October of each year), and broad national descriptions. The Library Journal "Placements and Salaries Survey" has a relatively low response rate $(51 \%$ in $2002,37 \%$ in 2003 ) and reports no greater detail than the category, "College and University." ${ }^{1}$ The federal Occupational Outlook Handbook is even less specific, saying only that "most" of the 167,000 librarians in 2002 worked in school or academic libraries. ${ }^{2}$

Researchers in library science have several ways of identifying their desired "sample" (more often, a defined entire population). One method is convenience or self-selection, such as in listserv solicitations. For example, Mayer and Terrill solicited Florida librarians for a study of attitudes toward subject masters, reporting respondents' distribution as to doctoral, master's, or baccalaureate or community college employment. ${ }^{3}$

Another tactic is to adopt a pre-existing grouping. For example, to study

Rachel Applegate is Assistant Professor at Indiana University at Indianapolis; e-mail: rapplega@iupui.edu. 


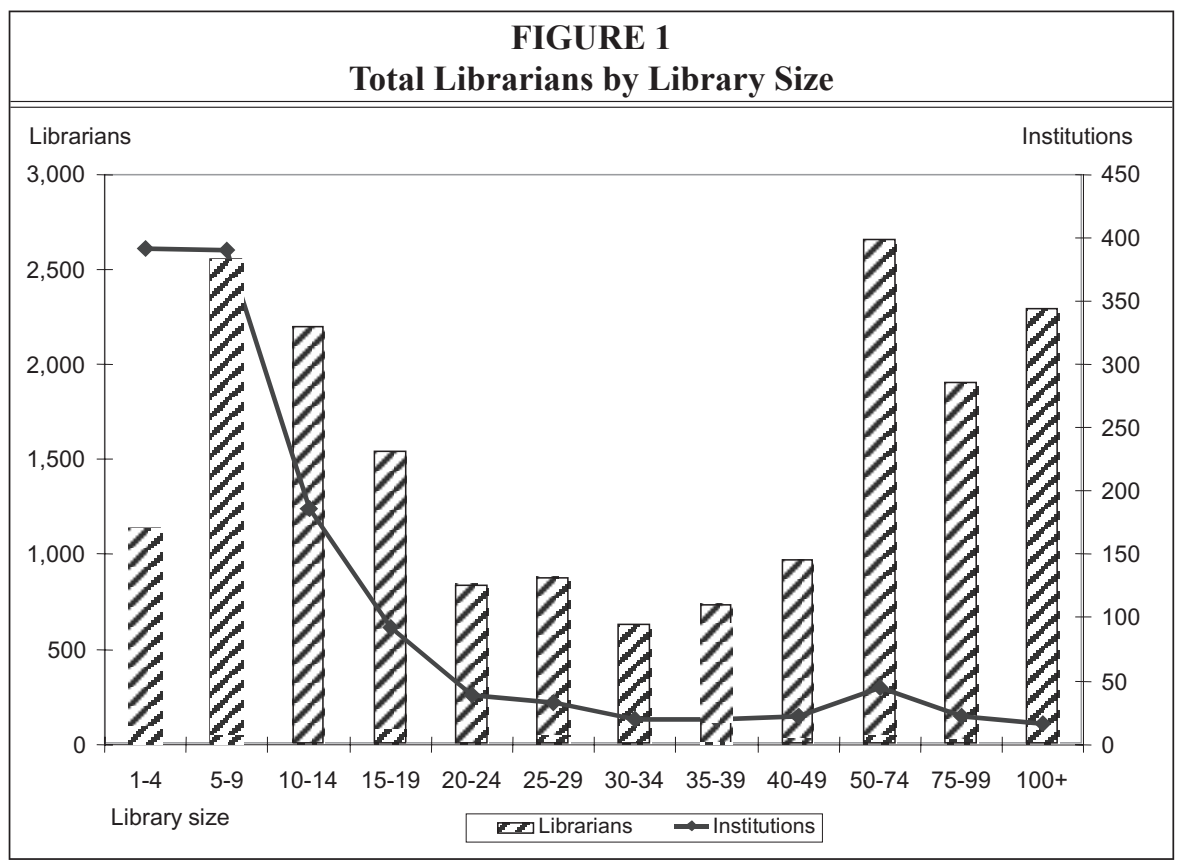

the structural relation of information technology and libraries, Bolin selected land-grant universities. ${ }^{4}$ The Association of Research Libraries (ARL) membership is an especially popular choice; SPEC Kits are one example of a series of surveys drawn from ARL membership, as is also the long-running ARL statistical data available on the web.

The ACRL 2004 "Standards for Libraries in Higher Education" recommends that libraries establish a peer group for analysis by a set of "points of comparison," such as "ratio of FTE library staff to combined student and faculty FTE." ${ }^{5}$

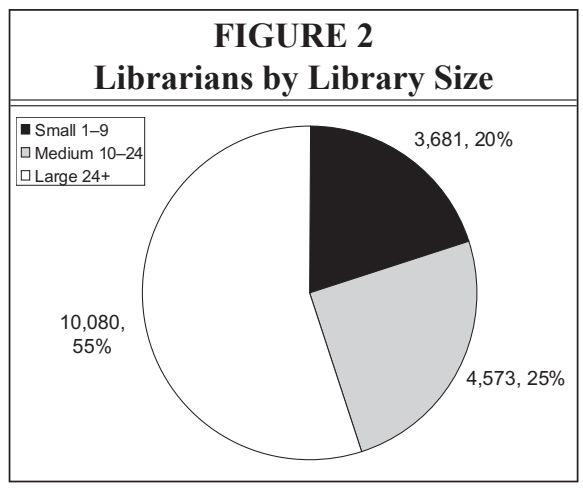

The Standards list a sampling of criteria through which the peer group may be determined: "mission, reputation, selectivity for admission, size of budget, size of endowment, expenditure for library support, and/or size of collection." For a given library, the construction of such a peer group will likely be determined on an allcampus basis, to gain greater legitimacy with university administrators, although it may lose some library comparability; for example, one small (2,500 students) private master's-level institution's peer group listing, created from nominations from academic departments, included

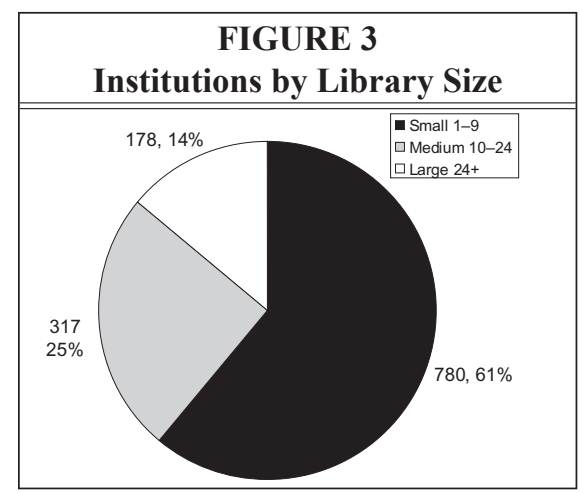


the College of St. Catherine $(4,800$ students), Augsburg College $(3,300)$, and Indiana University Purdue University Indianapolis $(30,000){ }^{6}$

An important resource is the Association for College and Research Libraries' own survey (first reported in 1999). ${ }^{7}$ Because it is librarian-designed, it allows for more in-depth examination of particular issues (e.g., faculty status elements in the 2002 survey).

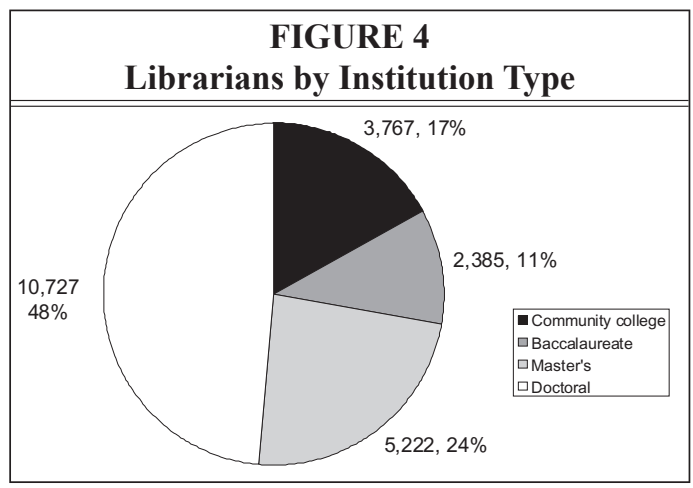
However, it has two major drawbacks. First, although summaries are posted on the Web site of the American Library Association, more detailed data is inaccessible without purchase of print volumes or electronic access, representing a considerable cost for a small library. Second, its response rate has remained below 50\%.

A much more comprehensive resource for institutional comparisons is organized by the federal National Center for Education Statistics. In contrast to the ACRL survey, even though there is no longer any federal sanction behind the Academic Libraries Survey (ALS), of the

1,380 institutions in the universe defined below and supplying IPEDS data, 1,292 or $94 \%$ also supplied ALS data. This creates an accessible, relatively comprehensive data resource.

The NCES compiles the results of the biannual ALS into a "Compare Academic Libraries" tool. $^{8}$ At that site, users can choose factors on which to retrieve and construct lists of peer libraries. Further, the site provides national and state averages for the variables chosen. The interface is user-friendly and the underlying data extraordinarily valuable; however, it can be difficult to derive general "land-

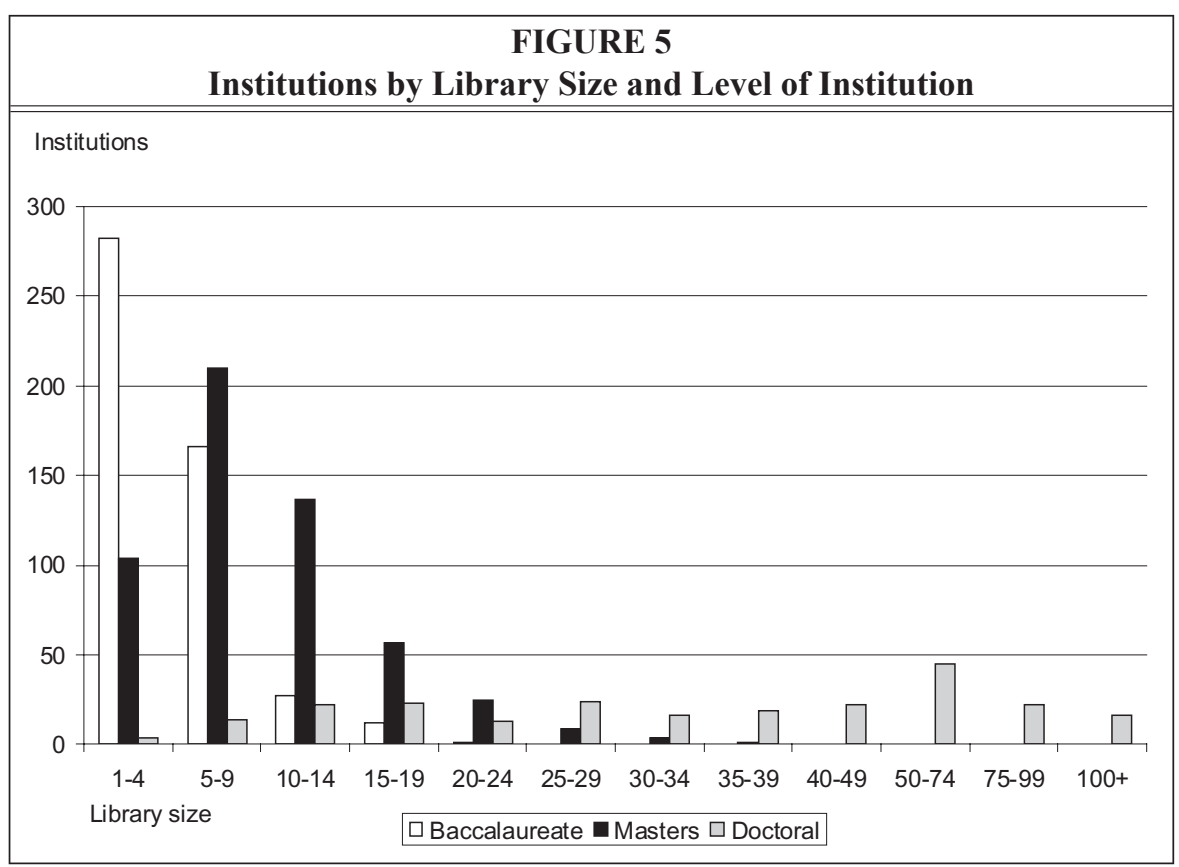




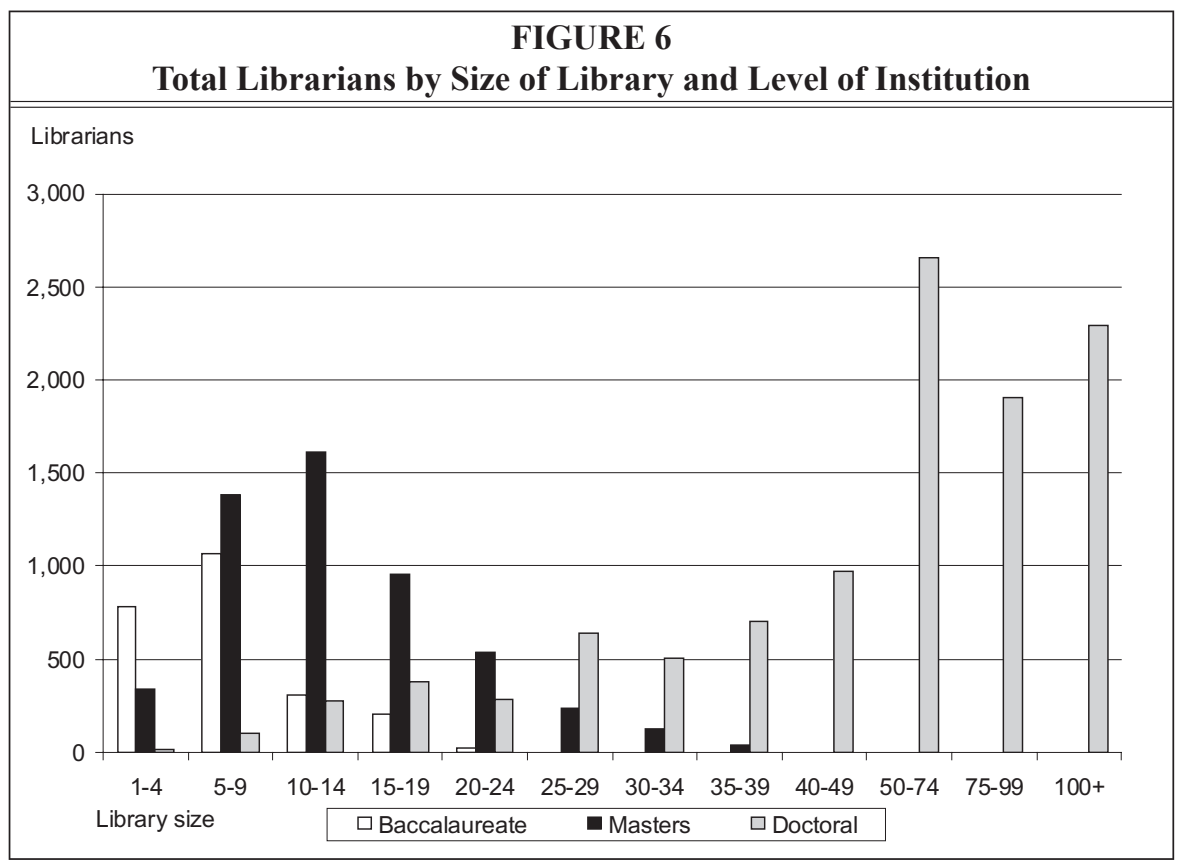

scape"-level descriptions via the preset options.

\section{Methodology: 2002 ALS-IPEDS Database}

These tables and figures were derived from a database consisting of data downloaded from two resources provided by the $\mathrm{Na}$ tional Center for Education Statistics: Compare Academic Libraries/ALS and the Integrated Postsecondary Educational Data Service (IPEDS). The Academic Library Survey is completed every two years, with an approximately two-year delay in public posting via the Compare Academic Libraries interface. The IPEDS surveys, which do not include library items but which feed FTE student data to the Compare Academic Libraries site, are completed every year by institutions receiving federal funds, are posted within months, and remain available for years.

The universe as selected for this database consists of all Carnegie classified doctoral, master's and baccalaureate institutions. ${ }^{9}$ Omitted were any institutions with a specialized classification:

- Theological seminaries and other specialized faith-related institutions

- Medical schools and medical centers; other separate health profession schools

- Schools of engineering and technology

- Schools of business and management

- Schools of art, music, and design

- Schools of law

- Teachers colleges

- Other specialized institutions

- Private-for-profit: twenty four-year nonspecialized institutions ${ }^{10}$

\begin{tabular}{|l|c|c|c|c|c|c|}
\hline \multicolumn{7}{|c|}{ TABLE 1 } \\
Other Library Staff to Librarians by Library \\
Size Excludes Student Workers \\
\hline \hline & \multicolumn{5}{|c|}{ Public } & \multicolumn{4}{c|}{ Private } \\
\hline & N & Average & SD & N & Average & SD \\
\hline Large & 124 & 2.1 & 0.6 & 54 & 1.8 & 0.6 \\
\hline Medium & 250 & 1.7 & 0.6 & 125 & 1.4 & 0.6 \\
\hline Small & 169 & 1.7 & 1.0 & 627 & 1.2 & 0.8 \\
\hline
\end{tabular}




\begin{tabular}{|l|r|r|r|r|r|r|}
\hline \multicolumn{7}{|c|}{ TABLE 2 } \\
Other Library Staff to Librarians by Carnegie \\
Classification \\
\hline \hline \multicolumn{7}{|c|}{ Excludes Student Workers } \\
\hline & \multicolumn{1}{|c|}{ N } & Avg. & SD & N & Avg. & SD \\
\hline & 99 & 2.2 & 0.7 & 46 & 1.9 & 0.6 \\
\hline Doctoral-Extensive & 59 & 2.0 & 0.8 & 37 & 1.6 & 0.6 \\
\hline Doctoral-Intensive & 241 & 1.7 & 0.1 & 218 & 1.3 & 0.6 \\
\hline Master's-I & 20 & 1.4 & 0.6 & 69 & 1.0 & 0.6 \\
\hline Master's-II & 17 & 1.9 & 1.8 & 173 & 1.4 & 0.7 \\
\hline Bacc-Liberal Arts & 39 & 1.4 & 1.0 & 223 & 1.2 & 0.9 \\
\hline Bacc-General & 13 & 1.6 & 0.8 & 24 & 0.8 & 0.8 \\
\hline Bacc-Assoc & 59 & & \\
\hline $\begin{array}{l}\text { N = number of institutions with valid data } \\
\text { SD = standard deviation }\end{array}$ \\
\hline
\end{tabular}

sites (branches) are distinct campuses or not is determined by each institution in conjunction with the Department of Education.

The database for most of these charts does not include associate-level institutions. Associate (community) colleges employ $18 \%$ of academic librarians, as illustrated in Figure 4. Of 1,127 respondents to the Academic Libraries Survey, the size of the librarian staff ranged from 0 for 33 institutions to 54 for the largest. Because community colleges often consist of systems

Included were institutions in these Carnegie classifications:

- Doctoral-Extensive

- Award over 50 doctoral degrees in over 15 disciplines

- Doctoral-Intensive

- Award over 20 doctoral degrees overall; or over 10 each in three or more disciplines

- Master's-I

- Award over 40 master's degrees in three or more disciplines

- Master's-II

- Award over 20 master's degrees overall

- Baccalaureate

- Liberal Arts: At least $50 \%$ of baccalaureate degrees are in liberal arts fields

- General: Less than 50\% of baccalaureate degrees in liberal arts fields

- Associate's: Fewer than $50 \%$ but more than $10 \%$ of institution's degrees are at baccalaureate level

In the database, "institution" refers to an individual college or university. Each institution is identified by IPEDS with a unique "institutional ID." Whether different educational with widely differing configurations of physical spaces and staffing, they are not included in most of the charts, ratios, and discussion that follow.

These tables and figures depict the landscape of four-year academia in terms of institutions and librarians, and present several key ratios that fill out the picture of what working in a particular library might be like: for instance, how many support staff there are per librarian, and how many students and faculty are served by each librarian.

\section{Findings: Distribution of Librarians}

Figure 1 displays how many librarians work in, and how many institutions there

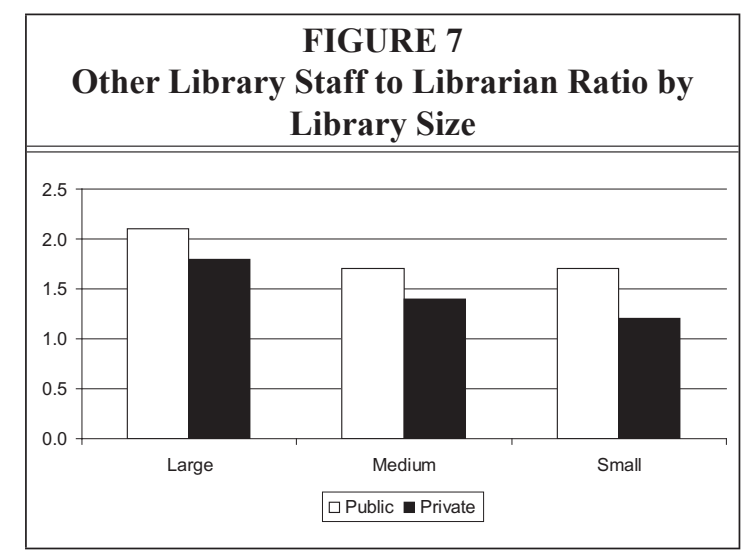




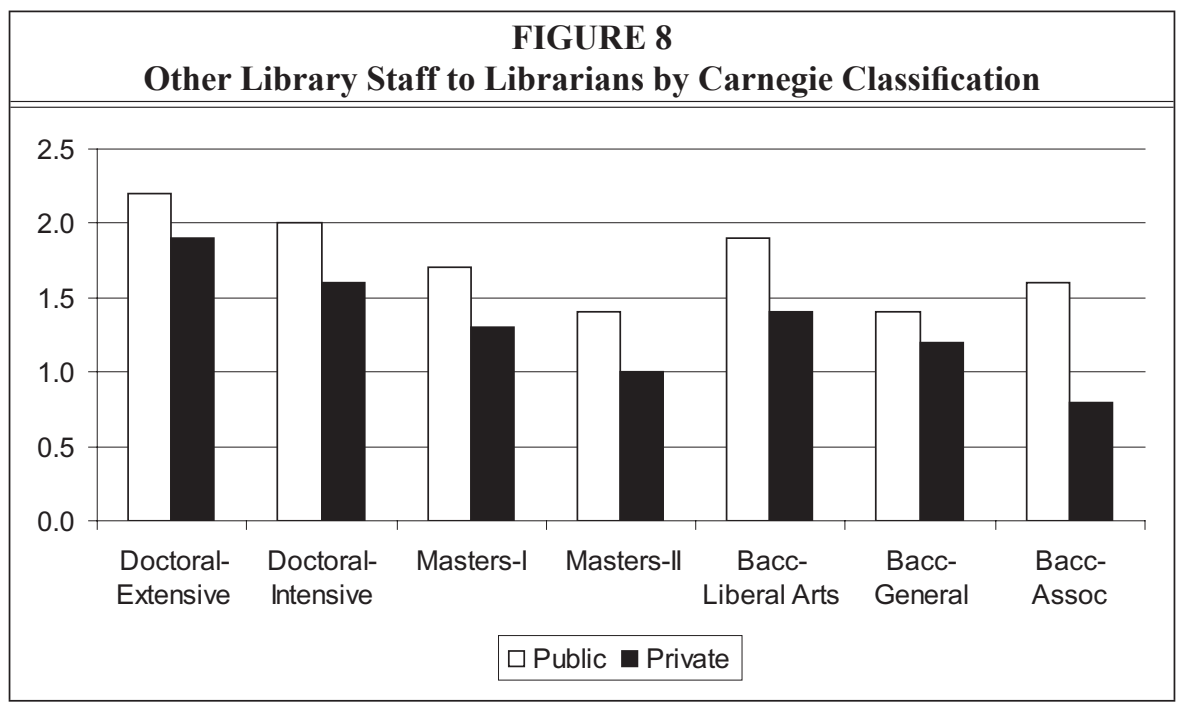

are with, libraries of particular sizes, from the smallest to the largest. "Size" indicates the size of the "librarian" staff. The ALS categorizes library personnel as "librarians," "other professional staff," "all other paid staff" and "student assistants." Unlike the Compare Public Libraries survey and site, it does not specify the ALA-MLS in the definition of librarian but rather, "The total FTE of staff whose duties require professional education (the master's degree or its equivalent) in the theoretical and scientific aspects of librarianship." 12 The "other professional staff" category is defined as "staff whose duties require education and/or training in related fields (e.g., academic disciplines, archives, media, computing)"; the category represents 4,565 people across

\begin{tabular}{|c|c|c|c|c|c|c|}
\hline \multicolumn{7}{|c|}{$\begin{array}{c}\text { TABLE } 3 \\
\text { Instructional Employees to Librarians } \\
\text { by Library Size }\end{array}$} \\
\hline & \multicolumn{3}{|c|}{ Public } & \multicolumn{3}{|c|}{ Private } \\
\hline & $\mathbf{N}$ & Avg. & SD & $\mathbf{N}$ & Avg. & SD \\
\hline Large & 99 & 22 & 14 & 38 & 24 & 13 \\
\hline Medium & 205 & 31 & 15 & 118 & 32 & 35 \\
\hline Small & 152 & 40 & 29 & 616 & 39 & 31 \\
\hline \multicolumn{7}{|c|}{$\begin{array}{l}\mathrm{N}=\text { number of institutions with valid data } \\
\mathrm{SD}=\text { standard deviation }\end{array}$} \\
\hline
\end{tabular}

the 1,380 institutions, as compared with a total of 18,487 librarians.

It can be seen from the line (numbers of institutions) that there are very many small libraries and few large ones, but the bars (total librarians) show that most librarians work in large or small institutions. This is even clearer when the library sizes are condensed to three categories, in Figure 2: over half of all academic librarians work in large libraries (with twenty-three or more other librarians), while the great majority of institutions have small libraries (Figure 3). The definition of small, medium, and large were derived from a connection between size and Carnegie classification: there is a distinct drop-off of baccalaureate institutions above 9 librarians, and there are no "large" baccalaureate institutions (more than 24 librarians); only 3\% of master's institutions are "large."

An analysis by Carnegie classification shows a similar pattern. Figure 4 summarizes doctoral, master's, and baccalaureate categories, and adds approximate data for community colleges. It shows that $54 \%$ of estimated academic librarians work at doctoral institutions.

Figure 5 and 6 give more detailed information, cross-cutting Carnegie classification with library size, for 


\begin{tabular}{|c|c|c|c|c|c|c|}
\hline \multicolumn{7}{|c|}{$\begin{array}{c}\text { TABLE } 4 \\
\text { Instructional Employees to Librarians by } \\
\text { Carnegie Classification }\end{array}$} \\
\hline & \multicolumn{3}{|c|}{ Public } & \multicolumn{3}{|c|}{ Private } \\
\hline & $\mathbf{N}$ & Avg. & SD & $\mathbf{N}$ & Avg. & SD \\
\hline Doctoral-Extensive & 79 & 23 & 20 & 33 & 22 & 13 \\
\hline Doctoral-Intensive & 43 & 31 & 14 & 33 & 52 & 44 \\
\hline Master's-I & 213 & 35 & 20 & 212 & 44 & 37 \\
\hline Master's-II & 17 & 36 & 20 & 67 & 37 & 18 \\
\hline Bacc-Liberal Arts & 17 & 28 & 14 & 168 & 26 & 9 \\
\hline Bacc-General & 34 & 36 & 20 & 218 & 36 & 27 \\
\hline Bacc-Assoc & 10 & 62 & 62 & 24 & 45 & 23 \\
\hline
\end{tabular}

student workers. Consistently, public institutions have a greater proportion of nonlibrarians as part of their total staff-put another way, they have fewer librarians as a portion of their staffing.

Librarians at public institutions also serve more instructional employees and students than do those at private institutions, at all sizes and Carnegie classifications. Tables 3 and 4 and Figures 9 and 10 display ratios for instructional employees (professors and

institutions (many small baccalaureate institutions; a few large doctoral institutions) and librarians (many employed at small baccalaureate institutions but the majority in larger, doctoral-level institution libraries).

\section{Findings: Ratios}

Essential elements of librarian working conditions include the level (Carnegie classification) and size of the library described above, but also important are staffing ratios, both internal (colleagues) and external (persons served). The tables and graphs for these ratios are divided between public and private institutions, as there are distinct, systematic differences in institutional character associated with these funding structures, and differences in ratios as will be seen. "Private" here includes only not-for-profit institutions. Twenty for-profit institutions were omitted from the data.

In general, each academic librarian works alongside between one and two nonstudent nonlibrarians. (See Table 1 and 2 and Figure 7 and 8.) This ratio includes other professional staff as defined above, and "all other" staff and excludes others), using data from the IPEDS Employees by Assigned Position survey. ${ }^{13}$ This includes part- and full-time persons, but is a headcount, not reduced to FTE as is the student ratio, shown in Tables 5 and 6 and Figures 11 and 12. Again, librarians at private institutions generally have lower ratios for students and instructional staff served.

\section{Summary}

The academic landscape thus is one in which:

- the majority of academic librarians work where they have more than 24 colleagues;

- most librarians at baccalaureate colleges have about four colleagues (most at master's institutions have about 14; most






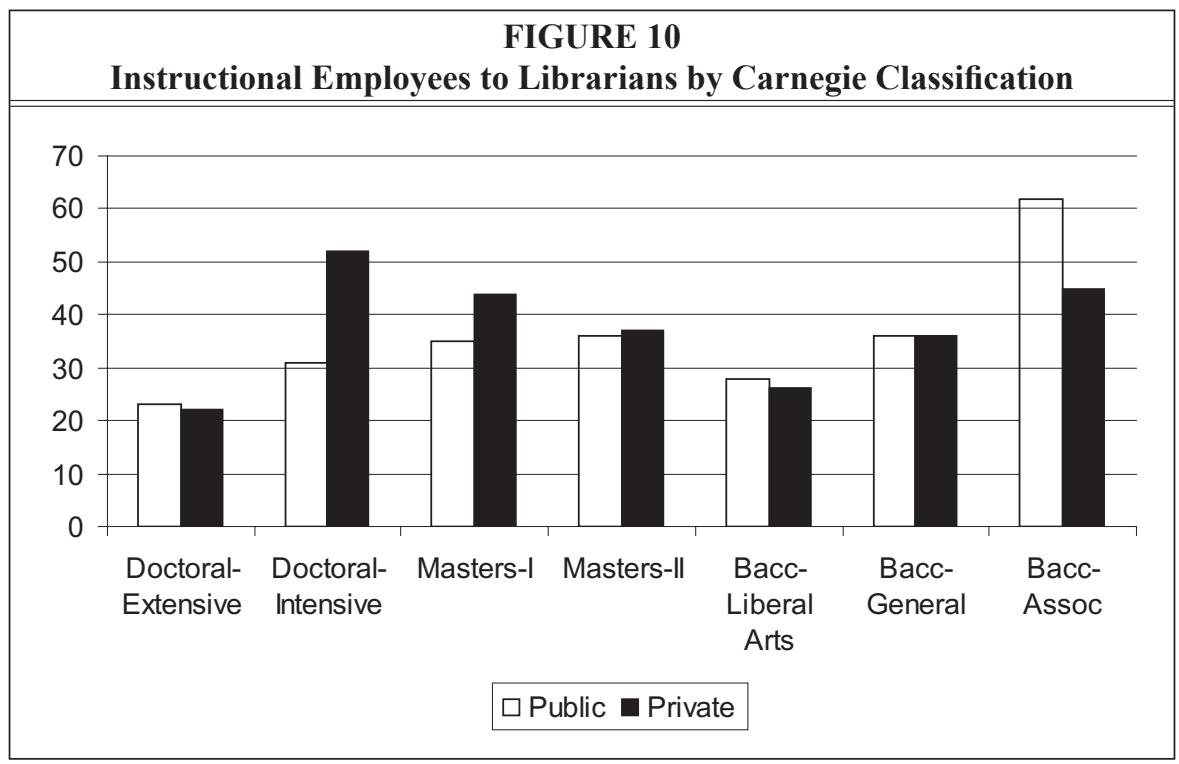

working in doctoral institutions have over 50 colleagues);

- in larger libraries, there are usually about two nonlibrarian staff members to each librarian (in small private institutions the ratio is closer to one-to-one);

- librarians at larger libraries generally serve fewer faculty members -22 to one vs. 30 or 40 to one at medium and small institutions, and fewer students (about 100 fewer students per librarian);

- librarians in private colleges and universities serve fewer faculty and students than those in public institutions - the smallest student-to-librarian ratio is in private liberal arts colleges, which matches their usual promotional claims of more personal attention.

\begin{tabular}{|l|c|c|c|c|c|c|}
\hline \multicolumn{7}{|c|}{ TABLE 5 } \\
FTE Students to Librarians by \\
Library Size \\
\hline \hline & \multicolumn{7}{|c|}{ Public } & \multicolumn{3}{c|}{ Private } \\
\hline & N & Avg. & SD & N & Avg. & SD \\
\hline Large & 124 & 466 & 162 & 54 & 223 & 107 \\
\hline Medium & 250 & 507 & 234 & 125 & 325 & 180 \\
\hline Small & 169 & 574 & 292 & 627 & 423 & 340 \\
\hline $\begin{array}{l}\text { N = number of institutions with valid data } \\
\text { SD = standard deviation }\end{array}$ \\
\hline
\end{tabular}

Different readers will find different elements of these findings striking. A very informal survey of about a dozen librarians evoked guesses that five to ten percent of librarians worked in large libraries. However, the opposite is true: a few very large libraries employ a great number of librarians. This means that the numerous research studies conducted at Association of Research Libraries appear to have a wide applicability - findings in and about large organizations will truly affect a large number of librarians. Books on complex library management issues have wide applicability for libraries with fifty or more librarians and staff members.

On the other hand, it is important to continue to recognize the significant portion of librarians who work in much smaller institutions, where institutional culture (particularly with respect to the teaching-research balance and value placed on individual attention), available resources and management configurations can feel very different from the large-library universe. Management issues relevant to the four-to-ten person organization affect over 20 percent of academic librarians. 
For researchers, whether the unit of analysis is a library or an individual librarian, these data allow comparisons of survey responses to the larger population. For example, in the Mayer and Terrill study of librarians' attitudes toward second degrees, the distribution of survey respondents gathered via listserv solicitation was statistically significantly different $(p<.01)$ from that expected from the national data.

It was significantly overweighted for respondents from doctoral institutions; one might speculate that it is in those institutions that a master's degree may be the most salient. Statistical tests for proportion can be employed to determine if respondents as defined by characteristics such as employment at large or small institutions, or Carnegie types, are similar to the population of interest.

In summary, these data provide a set of general bench-
TABLE 6

FTE Students to Librarians by

Carnegie Classification

\begin{tabular}{|l|r|c|c|r|c|c|}
\hline & \multicolumn{3}{|c|}{ Public } & \multicolumn{3}{c|}{ Private } \\
\hline & \multicolumn{1}{|c|}{ N } & Avg. & SD & \multicolumn{1}{|c|}{ N } & Avg. & SD \\
\hline Doctoral-Extensive & 99 & 454 & 144 & 46 & 217 & 106 \\
\hline Doctoral-Intensive & 59 & 560 & 191 & 37 & 465 & 247 \\
\hline Master's-I & 241 & 585 & 220 & 218 & 428 & 221 \\
\hline Master's-II & 20 & 557 & 174 & 67 & 447 & 227 \\
\hline Bacc-Liberal Arts & 17 & 470 & 196 & 173 & 256 & 103 \\
\hline Bacc-General & 39 & 521 & 228 & 223 & 411 & 292 \\
\hline Bacc--Assoc & 13 & 914 & 592 & 24 & 496 & 384 \\
\hline $\begin{array}{l}\text { N = number of institutions with valid data } \\
\text { SD = standard deviation }\end{array}$
\end{tabular}

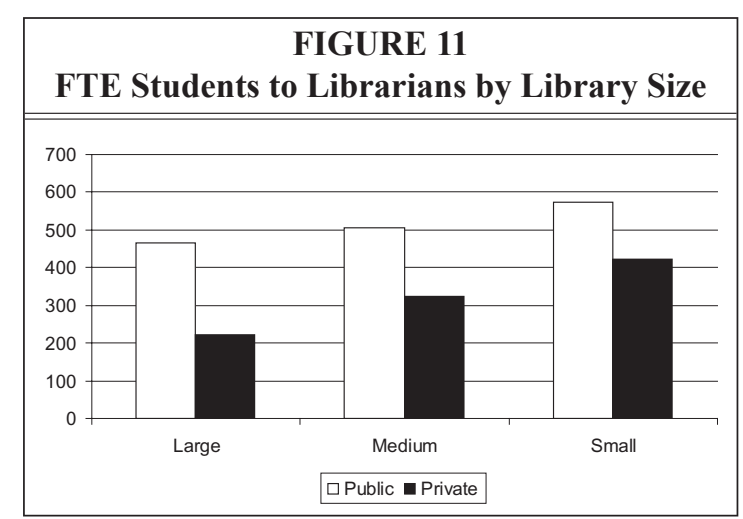

FIGURE 12

FTE Students to Librarians by Carnegie Classification






\section{TABLE 7 \\ Comparison of Survey Respondents to National Proportions}

\begin{tabular}{|l|c|c|}
\hline \hline & $\begin{array}{c}\text { Mayer } \\
\text { and } \\
\text { Terrill* }\end{array}$ & $\begin{array}{c}\text { Expected } \\
\text { from } \\
\text { National } \\
\text { Data }\end{array}$ \\
\hline Doctoral & 691 & 582 \\
\hline Masters & 303 & 291 \\
\hline Baccalaureate & 109 & 133 \\
\hline Community & 109 & 206 \\
\hline $\begin{array}{l}\text { *Estimated from } \\
\text { text percentages }\end{array}$ & $\mathrm{p}<.01$ & \\
\hline
\end{tabular}

marks in library assessment, description, and management. ${ }^{14}$

Any library with an existing and accepted list of peer institutions can retrieve relevant data with comparative ease from the Compare Academic Libraries site, and with a little more difficulty from the main IPEDS site-a university's institutional researcher can assist with this. However, when a peer group has not been established, or if only broad comparisons are desired, the data presented here provide more detail than that available from most other sources.

\section{Notes}

1. Stephanie Maatta, “Jobs! (Eventually)," Library Journal 129 (Oct. 15, 2004): 28-35; S. Maatta, "Salaries Stalled, Jobs Tight," Library Journal 128 (Oct. 15, 2003): 28-32, 34.

2. Bureau of Labor Statistics, U.S. Department of Labor, "Librarians," Occupational Outlook Handbook, 2004-05 Edition. Available online at www.bls.gov/oco/ocos068.htm. [Accessed 17 August 2005].

3. Jennifer Mayer and Lori J. Terrill, “Academic Librarians' Attitudes About Advanced-Subject Degrees," College E Research Libraries 66 (2005): 59-73.

4. Mary K. Bolin, "The Library and the Computer Center: Organizational Patterns at Land Grant Universities," Journal of Academic Librarianship 31 (2005): 3-11.

5. Association of College and Research Libraries. 2004. Standards for Libraries in Higher Education. Available online at www.ala.org/ala/acrl/acrlstandards/standardslibraries.htm. [Accessed 30 November 2004].

6. Personal communication.

7. H. A. Thompson, "ACRL Wraps up Year 1 of Academic Library Statistics Project: How You Can Get the Results," College \& Research Libraries News 60 (Oct. 1999): 760-61.

8. Currently available online at http://nces.ed.gov/surveys/libraries/compare/index.asp?Lib raryType=Academic. [Accessed 18 August 2005]. The site has moved frequently, so an ed.gov or Google search may be the most effective means of accessing it.

9. Eighty-eight institutions did not respond; four doctoral-extensive universities: University of Delaware, University of Maryland-Baltimore County, California Institute of Technology, and Stanford University; five doctoral-intensive; nineteen masters-I; eleven masters-II, and forty-nine baccalaureate institutions. Their total student FTE is 188,420 , which is $2.5 \%$ of the $7,475,111$ FTE for all institutions.

10. Definitions from the IPEDS Web site. Available online at http://nces.ed.gov/ipeds/. [Accessed 20 July 2005].

11. U.S. Department of Education, National Center for Education Statistics, "Table 175. Total fall enrollment in degree-granting institutions, by control and type of institution: 1965 to 2001," Digest of Education Statistics, 2003. Available online at http://nces.ed.gov/programs/digest/d03/ tables/dt175.asp. [Accessed 18 August 2005).

12. IPEDS, see above.

13. "A primary function or occupational activity category used to classify persons whose specific assignments customarily are made for the purpose of conducting instruction or teaching and who hold academic titles of professor, associate professor, assistant professor, instructor, lecturer or the equivalent. Includes deans, directors, or the equivalent, as well as associate deans, assistant deans, and executive officers of academic departments (chairpersons, heads, or equivalent) if their principal activity is instruction," text from the "Definition Bank," ANSWERS. Available online at http://highered.org/answers/products/definitionsearch3.asp. [Accessed 20 August 2005].

14. Access to the database is available by contacting the author, Rachel Applegate, at: rapplega@iupui.edu. 